\title{
ESTIMATED INFLUENCE OF STRATOSPHERIC ACTIVITY ON THE IONOSPHERE ACCORDING TO MEASUREMENTS WITH ISTP SB RAS TOOLS
}

\author{
M.V. Tolstikov \\ Institute of Solar-Terrestrial Physics SB RAS, \\ Irkutsk,Russia,maxim@iszf.irk.ru \\ K.G. Ratovsky \\ Institute of Solar-Terrestrial Physics SB RAS, \\ Irkutsk,Russia,ratovsky@iszf.irk.ru
}

\author{
I.V. Medvedeva \\ Institute of Solar-Terrestrial Physics SB RAS, \\ Irkutsk, Russia,ivmed@iszf.irk.ru \\ A.M. Obukhov Institute of Atmospheric Physics RAS, \\ Moscow, Russia
}

D.S. Khabituev

Institute of Solar-Terrestrial Physics SB RAS,

Irkutsk,Russia,khabituev@iszf.irk.ru

\begin{abstract}
We present the results of a comprehensive study of the manifestation of wave activity with periods of internal gravity waves (IGW) in various regions of the atmosphere: in the stratosphere, upper mesosphere, and in the F2-region of the ionosphere. The study is based on radiophysical and spectrometric measurements made with tools of the Institute of Solar-Terrestrial Physics (ISTP) SB RAS and the Era-Interim reanalysis data. The correlation coefficient with time shift between ionospheric and stratospheric activity for the annual interval varies in the range from 0.45 to 0.54 , and for the 27-day interval it reaches the levels $0.4-0.8$ in seventy percent of the cases. Thirty percent of correlation coefficients less than 0.4 can be explained by the influence of neutral wind, geomagnetic activity, and nonstratospheric IGW sources. Comparison between stratospheric activity and variations in characteristics of trav-
\end{abstract}

eling ionospheric disturbances (TID) has shown that a $\sim 15$ day shift in stratospheric activity results in a fairly high correlation between stratospheric activity and disturbance of IGW characteristics $(\sim 0.6)$. The delay of about 15 days can be attributed to the delay in the temperature variations at heights of the lower thermosphere relative to the temperature variations at the altitude pressure level of $1 \mathrm{hPa}$. Comparative analysis of variations in mesospheric and ionospheric activity has revealed time intervals when their behavior is consistent.

Keywords: stratosphere, mesosphere, ionosphere, planetary waves, TID, IGW.

\section{INTRODUCTION}

The state of Earth's atmosphere is largely determined by the complex effect of dynamic, chemical, radiation, thermal, electrodynamic processes, as well as by the effect of solar and geomagnetic activity. Wave processes are the main mechanism of energy transfer between different regions of the atmosphere. Atmospheric waves can travel over long distances and transfer energy from the underlying layers to the upper atmosphere, providing the interconnection between the atmospheric layers. To date, experimental evidence has been obtained of the impact of strong meteorological disturbances, such as sudden stratospheric warming (SSW) events, on atmospheric parameters in the mesosphere and even in the thermosphere [Goncharenko, Zhang, 2008, Goncharenko et al., 2010, 2013; Pancheva, Mukhtarov, 2011; Korenkov et al., 2012; Polyakova et al., 2014; Medvedev et al., 2015, Tolstikov et al., 2019]. At present, however, there is no generally accepted theory of energy transfer from a meteorological phenomenon up to heights of the thermosphere. In this work, we tried to detect ionospheric responses over Irkutsk to disturbances in the stratosphere and mesosphere. The analysis of wave activity at stratospheric heights is based on the EraInterim reanalysis data on the vertical wind velocity at a pressure level of $1 \mathrm{hPa}(\sim 50) \mathrm{km}$. To analyze manifestations of wave activity in the upper mesosphere, we have used data on the rotational temperature of the hydroxyl molecule $(\mathrm{OH}$ (6-2) band, $834.0 \mathrm{~nm}, \sim 87 \mathrm{~km}$ emission height) obtained from spectrometric measurements at the ISTP SB RAS Geophysical Observatory $\left(51.8^{\circ} \mathrm{N}\right.$, $103.1^{\circ} \mathrm{E}$, Tory). To analyze manifestations of wave activity at ionospheric heights, we utilized values of the maximum electron density $N_{\mathrm{m}} \mathrm{F} 2$ according to the data from the Irkutsk $\left(52.3^{\circ} \mathrm{N}, 104.3^{\circ} \mathrm{E}\right)$ vertical sounding ionosonde (ionospheric activity) and characteristics of traveling ionospheric disturbances (TID) obtained from simultaneous measurements at the Irkutsk Incoherent Scatter Radar (IISR) and the Irkutsk ionosonde (disturbance of IGW characteristics). We also employed satellite measurements of vertical atmospheric temperature profiles from MLS Aura [http://disc.gsfc.nasa.gov/Aura] and data on the geomagnetic activity index $K_{\mathrm{p}}$ from the World Data Center (WDC Boulder, Colorado, [ftp://ftp.ngdc.noaa.gov/STP/GEOMAGNETIC_DATA/ INDICES/KP_AP]). 


\section{COMPARISON BETWEEN STRATOSPHERIC AND IONOSPHERIC ACTIVITY}

Most studies perform space-time spectral analysis to investigate the wave activity in the stratosphere [Hayashi, 1971]. For atmospheric parameters (mainly geopotential height, potential temperature, zonal velocity), the Fourier spectrum is calculated with waves of different wavenumbers identified [Pogoreltsev et al., 2015; Dell'Aquila et al., 2005]. Shpynev et al. [2015] carried out similar studies of wave activity of the stratosphere, using vertical velocity spectra. This approach to calculating the spectrum throughout the latitude circle is adequate for establishing global dependences and trends in the atmosphere, but it is poorly suited for revealing the variability of the atmosphere in a small local area. In this regard, to assess the stratospheric wave activity in the Irkutsk region, we have applied the following method. From the entire array of reanalysis data we took a sector with geographic coordinates $50^{\circ}-60^{\circ} \mathrm{N}$ and $90^{\circ}$ $120^{\circ} \mathrm{E}$ (the Irkutsk Region). As a measure of stratospheric activity, we used the measure of the spatial heterogeneity of data, specified by the standard deviation of the vertical velocity at the altitude pressure level of 1 $\mathrm{hPa}$ relative to the mean velocity for the sector under study. The unit of measurement of stratospheric activity is millipascal per second $(\mathrm{mPa} / \mathrm{s})$; the time resolution is 1 day. As a measure of ionospheric activity, we employed the rms value of relative disturbances of $N_{\mathrm{m}} \mathrm{F} 2$ in the range of IGW periods, obtained by averaging over one day. The relative disturbances of $N_{\mathrm{m}} \mathrm{F} 2$ in the range of IGW periods are relative deviations of $N_{\mathrm{m}} \mathrm{F} 2$ from running 27-day medians. With a low-frequency filter $(6$ hr boundary period), these disturbances were divided into low-frequency (periods longer than $6 \mathrm{hr}$ ) and highfrequency (less than $6 \mathrm{hr}$ ) components. The highfrequency component was utilized as disturbances in the IGW range. The unit of measurement of ionospheric activity is percent (\%), and the time resolution is 1 day.

The main mechanism of energy transfer between different layers of the atmosphere is thought to be wave processes. It is therefore necessary to take into account the complexity of this problem, when comparing stratospheric and ionospheric activity.

First, it takes some time for a wave to propagate from the stratosphere to the thermosphere; therefore, we can expect a delay in variations of stratospheric and ionospheric activity. It may be different for different time intervals due to the interference of several disturbances and the change in wave characteristics.

Second, the neutral wind has a significant effect on propagation conditions for internal gravity waves (IGW). When IGW propagate downwind, critical layers in which IGW are absorbed may appear at some heights. Thus, critical layers can block IGW propagation to ionospheric heights. When IGW propagate upwind, there may be layers of horizontal and vertical reflections; these layers also impede IGW propagation to ionospheric heights. When vertical reflection layers appear and there is no critical layer between them, waveguide IGW propagation can occur such that a wave is locked be- tween two layers along the vertical and the wave disturbance travels far from the IGW generation source in the horizontal plane. The horizontal drift of the IGW package may be as long as thousands of kilometers [Erokhin et al., 2007a, b; Suslov et al., 2017]. Thus, variations in the neutral wind may lead to a decrease in the correlation between stratospheric and ionospheric activity.

Third, geomagnetic activity, non-stratospheric IGW sources, ionospheric variations unrelated to IGW, but in the range of IGW periods, also cause a decrease in the correlation between stratospheric and ionospheric activity.

To compare annual variations in ionospheric and stratospheric activity for 2011-2016, we have calculated correlation functions between them for each year, and have found time shifts (in the range of 0 to 35 days), which provide maxima of the corresponding correlation functions [Bat, 1980]. Maximum of the correlation function $K(\tau)$ is called hereinafter the shear correlation coefficient:

$$
K(\tau)=\frac{\sum((S(t-\tau)-\bar{S})(I(t)-\bar{I})}{\sigma S \sigma I},
$$

where $S$ is stratospheric activity; $I$ is ionospheric activity; $\sigma(S)$ is the standard deviation of stratospheric activity; $\sigma(I)$ is the standard deviation of ionospheric activity.

Table 1 lists annual correlation coefficients between stratospheric and ionospheric activity for 2011-2016.

It can be seen that during all the years considered there is a mean correlation coefficient of $\sim 0.5$ between variations in stratospheric and ionospheric activity. To explain the delay in them, the following hypothesis has been put forward. If stratospheric and ionospheric activity were due to the same IGW flux, the delay would be several hours, but not days. An alternative version is that we observe different IGW fluxes that have the same cause - planetary wave activity.

Table 1

Annual correlation coefficients

between stratospheric and ionospheric activity

\begin{tabular}{|c|c|c|c|}
\hline Year & $\begin{array}{c}\text { Correlation } \\
\text { coefficient } \\
\text { without shear }\end{array}$ & $\begin{array}{c}\text { Correlation } \\
\text { coefficient } \\
\text { with shear }\end{array}$ & $\begin{array}{c}\text { Optimal shift } \\
\text { in days }\end{array}$ \\
\hline 2011 & 0.42 & 0.51 & 10 \\
\hline 2012 & 0.4 & 0.45 & 6 \\
\hline 2013 & 0.53 & 0.54 & 1 \\
\hline 2014 & 0.38 & 0.52 & 6 \\
\hline 2015 & 0.48 & 0.49 & 2 \\
\hline 2016 & 0.48 & 0.49 & 15 \\
\hline
\end{tabular}

It is assumed that the greatest IGW activity occurs during the phase of planetary wave maximum, ionospheric activity most strongly affected by disturbances in the mesopause region $(\sim 90 \mathrm{~km})$ [Medvedev et al., 2017; Tolstikov et al., 2019]. In this case, the delay in variations of stratospheric and ionospheric activity is explained by the delay in the planetary wave maximum at the mesopause $(\sim 90 \mathrm{~km})$ relative to the planetary wave maximum at the stratopause $(\sim 50 \mathrm{~km})$. Given that the characteristic vertical lengths of planetary waves are 
$\sim 20-150 \mathrm{~km}$ and their characteristic periods are $\sim 5-45$ days [Tolstikov et al., 2014], the delay of several days looks realistic. The delay in stratospheric and ionospheric activity during different years may differ due to changes in planetary wave characteristics.

As mentioned above, in addition to stratospheric activity, ionospheric activity is influenced by many factors, including magnetic activity. Figure 1 shows regression of correlation coefficients on geomagnetic activity $\left(K_{\mathrm{p}}\right.$ index $)$. As expected, during more magnetically quiet years, the correlation between stratospheric and ionospheric activity is higher.

Both stratospheric and ionospheric activity has a pronounced seasonal variation: in winter it is, on average, greater than in summer. However, along with the seasonal variation there are many smaller-period variations in stratospheric and ionospheric activity. To study them, it is necessary to analyze the correlation between stratospheric and ionospheric activity at shorter time intervals. Calculate the correlation coefficient without shear for each 27-day interval, the choice of which is based on the following considerations. On the one hand, the interval should include the amount of data required for the correlation analysis. On the other hand, the interval should correspond to approximately the same seasonal conditions. Thus, the 27-day interval is a compromise between these requirements.

Figure 2 shows the correlation coefficient without shear as a function of year (vertical axis) and day of the year (horizontal axis). Day of the year means that the correlation coefficient was calculated over an interval of \pm 13 days relative to the day of the year. The correlation coefficient is seen to undergo quasiperiodic variations from -0.6 to 0.6 , which can be explained as follows. As mentioned above, the delay in stratospheric and ionospheric activity variations can be explained by the delay in the planetary wave maximum at the mesopause $(\sim 90$ $\mathrm{km})$ relative to the maximum at the stratopause $(\sim 50$ $\mathrm{km})$. If stratospheric activity were supported by a single planetary wave, we would observe a constant correlation coefficient. Its decrease at each point would depend on the wave phase difference by 50 and $90 \mathrm{~km}$. A change in the phase difference during a year would not lead to quasiperiodic variations. They may be caused by the interference of several planetary waves. Tolstikov et al. [2014] have shown that temperature disturbances during stratospheric warming events in 2004-2013 were the interference of at least two planetary waves. The interference leads to quasiperiodic variations in the phase difference of the total wave by 50 and $90 \mathrm{~km}$, which, in turn, causes quasiperiodic variations in the correlation coefficient.

Figure 3 plots a shear correlation coefficient and an optimal shift in days as a function of year (vertical axis) and day of the year (horizontal axis). The shear correlation coefficients are seen to be on average significantly higher than the coefficients without shear correlation. The mean shear correlation coefficient is $\sim 0.47 ; 70 \%$ of the shear correlation coefficients between stratospheric and ionospheric activity are greater than 0.4 ; and $16 \%$, greater than 0.6 . These facts suggest that planetary waves

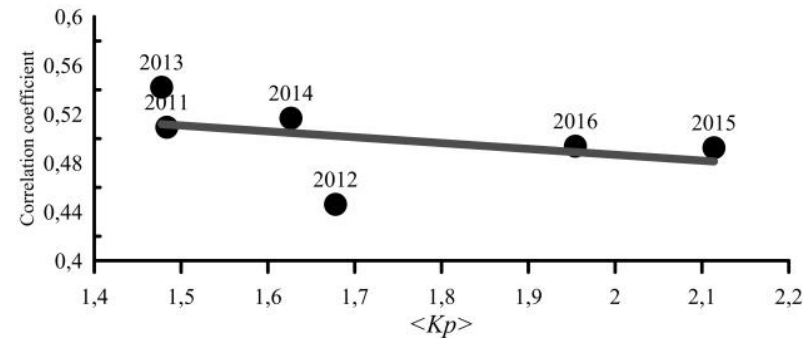

Figure 1. Regression of correlation coefficients between stratospheric and ionospheric activity (with optimal shift) on geomagnetic activity

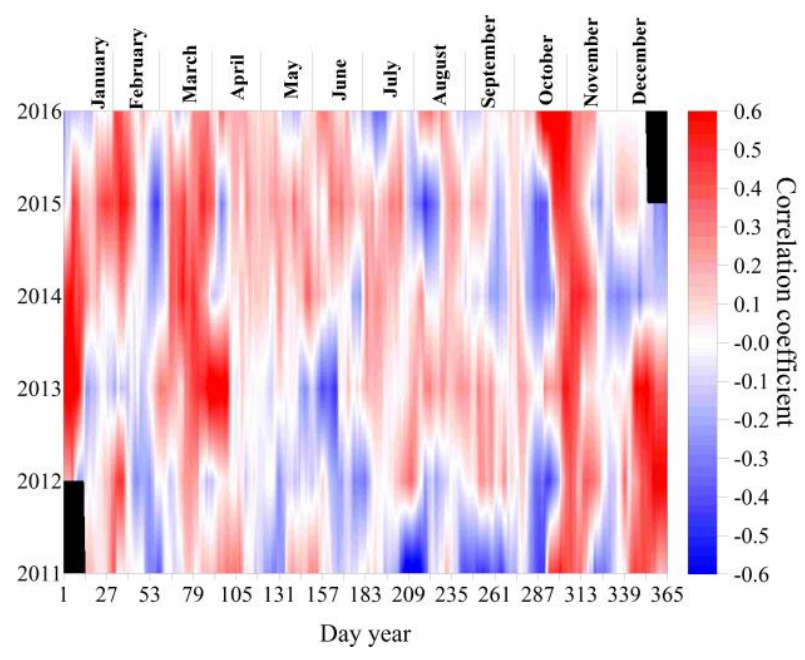

Figure 2. Correlation coefficients between stratospheric and ionospheric activity as a function of year (vertical axis) and day of the year (horizontal axis) for 27-day intervals (horizontal axis) for 27-day intervals

in the stratosphere affect the ionosphere; $30 \%$ of the shear correlation coefficients less than 0.4 can be explained by the influence of variations in the neutral wind, geomagnetic activity, and non-stratospheric IGW sources. Quasiperiodic variations in the optimal shift may be caused by beats due to the interference of several waves.

\section{COMPARISON BETWEEN STRATOSPHERIC ACTIVITY AND VARIATIONS IN TID CHARACTERISTICS}

Automatic methods of processing simultaneous measurements made with IISR and the Irkutsk ionosonde DPS-4 provided representative statistics of parameters of TID propagation in the ionosphere [Medvedev et al., 2015]. In this work, we have used the methods of numerical estimation of disturbances of TID parameter distributions, developed in [Tolstikov et al., 2019]. Using the entire volume of winter simultaneous measurements made with IISR and the Irkutsk ionosonde DPS-4, we calculated winter mean distributions of TID parameters.

The calculation results are presented in Figure 4. Then, we determined the correlation coefficients $K$ between the mean winter distributions of each parameter 

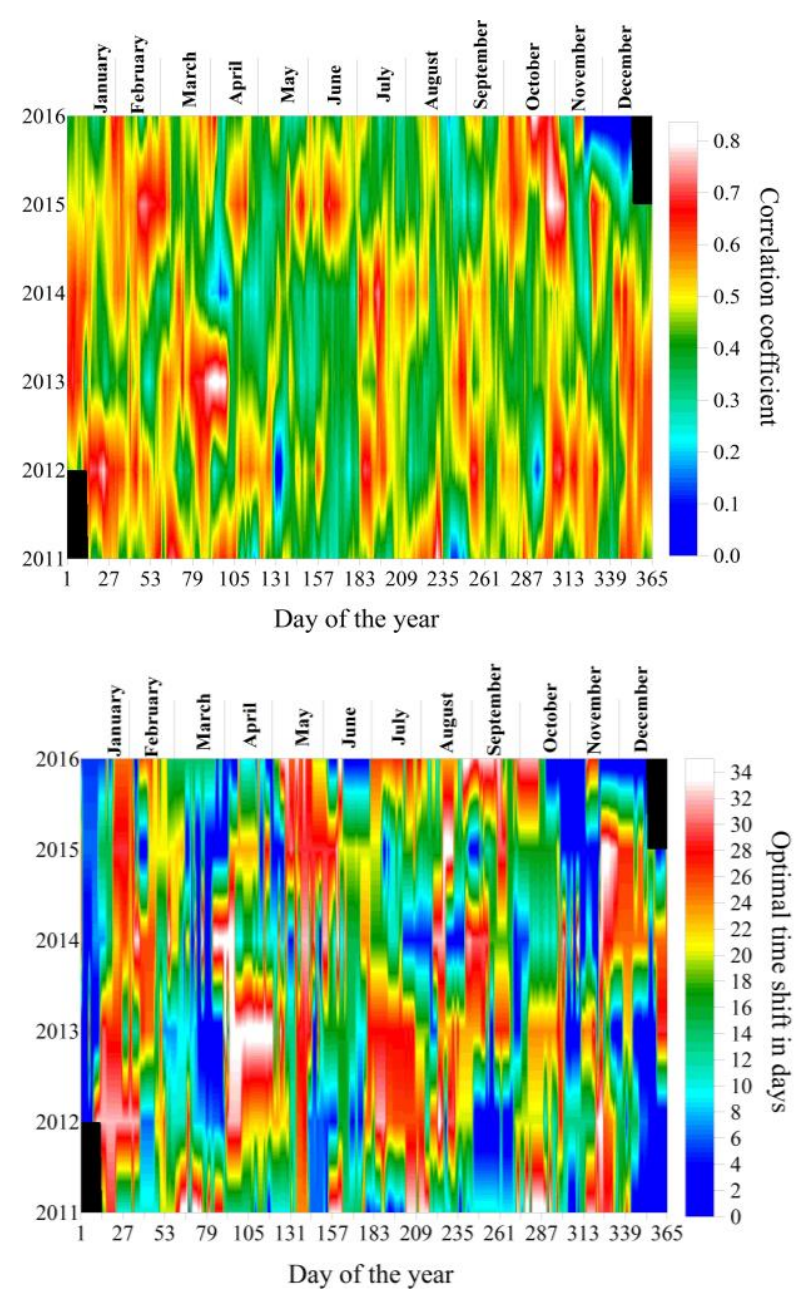

Figure 3. Shear correlation coefficient and optimal shift in days as a function of year (vertical axis) and day of the year and the distribution on a particular day.
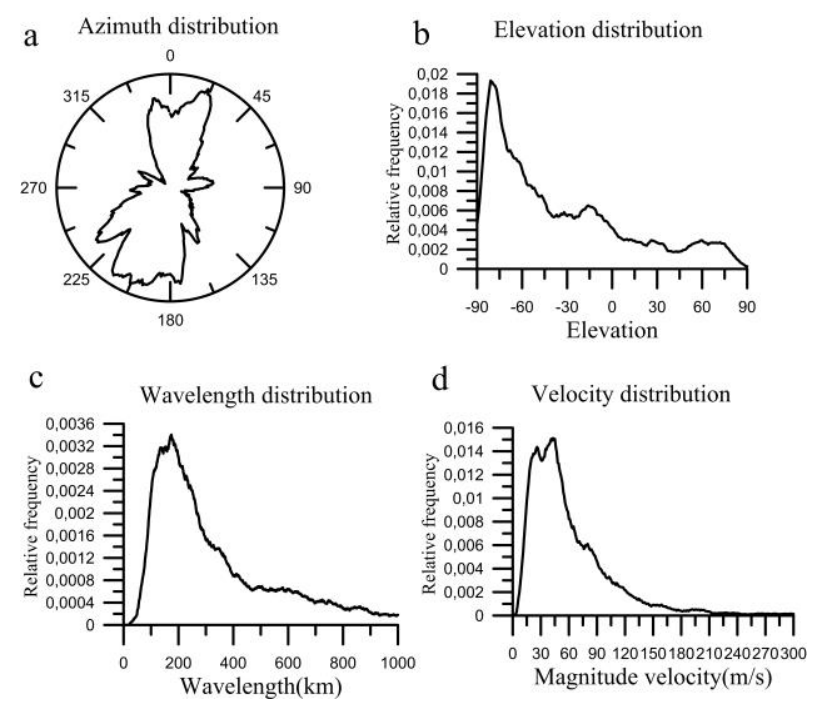

Figure 4. Winter average distributions of TID parameters: TID azimuths (a); elevations (angle to the horizon: positive upward, negative downward) $(b)$; wavelengths $(c)$; velocities $(d)$

The difference $1-K$ was assumed to be the degree of disturbance for each day in terms of the parameter (azimuth, elevation, wavelength, and velocity modulus). At
$K=1$, parameter distribution completely coincides with the winter mean distribution and the disturbance is equal to zero. At $K=0$, the disturbance is equal to 1 , at $K=-1$ it is equal to 2. Now we can compare the disturbance of each IGW parameter with stratospheric activity. The longest series of observations was obtained for 2011 (January 16 - February 16).

Figure 5 compares stratospheric activity and disturbance of IGW characteristics for the winter period of 2011 (January 16 - February 16) corresponding to the longest series of observation. Figure 5 and Table 2 indicate that with a $\sim 15$ days shift in stratospheric activity, a fairly high correlation is observed between stratospheric activity and disturbance of IGW characteristics. An increase or decrease in stratospheric activity and disturbance of IGW characteristics may result from a common cause - the impact of a strong planetary wave. In the former case, the planetary wave acts at the altitude pressure level of $1 \mathrm{hPa}$, whereas a change in the disturbance of IGW characteristics is associated with a change in the wind pattern in the lower thermosphere [Medvedev et al., 2017; Tolstikov et al., 2019]. The $\sim 15$ day delay in the disturbance of IGW characteristics may be explained by the corresponding delay in the temperature variations at heights of the lower thermosphere relative to the temperature variations at the altitude pressure level of $1 \mathrm{hPa}$. To estimate the reality of this delay, we used temperature data from the AURA satellite.

Figure 6 displays daytime temperatures over Irkutsk at heights of $\sim 50$ and $\sim 90 \mathrm{~km}$ for January 16 - February 16, 2011. Without a time shift, the correlation coefficient between temperatures at heights of $\sim 50$ and $\sim 90$ $\mathrm{km}$ was $\sim 0.21$, and with a shift of 19 days, it was $\sim 0.41$. The delay obtained from AURA satellite data (19 days) is comparable to the delay obtained by comparing stratospheric activity and the disturbance of IGW characteristics (15 days).

\section{COMPARISON OF MESOSPHERIC AND IONOSPHERIC ACTIVITY}

To analyze manifestations of wave activity in the upper mesosphere, we have used data on the rotational temperature of the hydroxyl molecule $(\mathrm{OH}(6-2)$

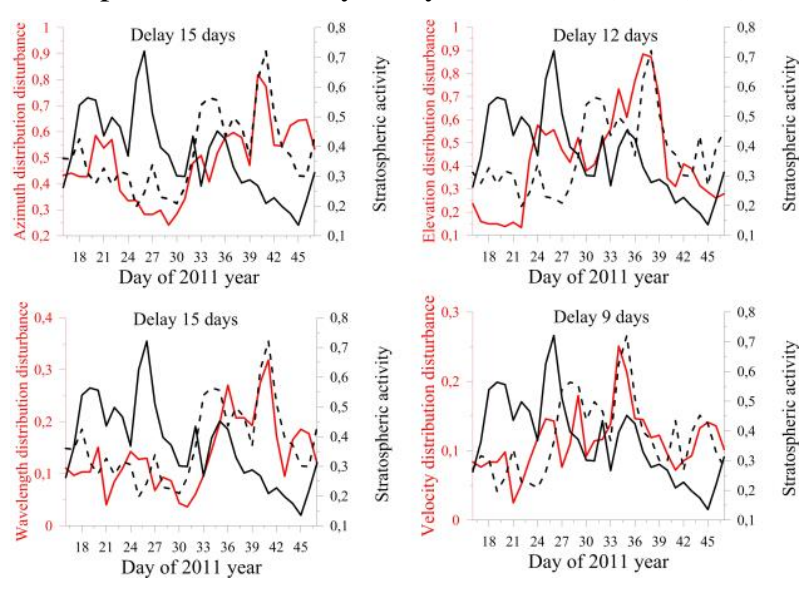

Figure 5. Comparison of stratospheric activity with the disturbance of TID characteristics for 2011. The black line indicates stratospheric activity; red, TID parameter disturbance; the black dashed line is stratospheric activity, shifted to achieve the maximum correlation coefficient 
Correlation coefficients between stratospheric activity and the disturbance of TID characteristics

\begin{tabular}{|l|c|c|c|}
\hline & $\begin{array}{c}\text { Correlation coefficient } \\
\text { without shear }\end{array}$ & $\begin{array}{c}\text { Correlation coefficient } \\
\text { with shear }\end{array}$ & $\begin{array}{c}\text { Optimal shift } \\
\text { in days }\end{array}$ \\
\hline Azimuth & -0.5 & 0.64 & 15 \\
\hline Elevation & -0.03 & 0.56 & 12 \\
\hline Wavelength & -0.3 & 0.66 & 15 \\
\hline Velocity & 0 & 0.6 & 9 \\
\hline
\end{tabular}
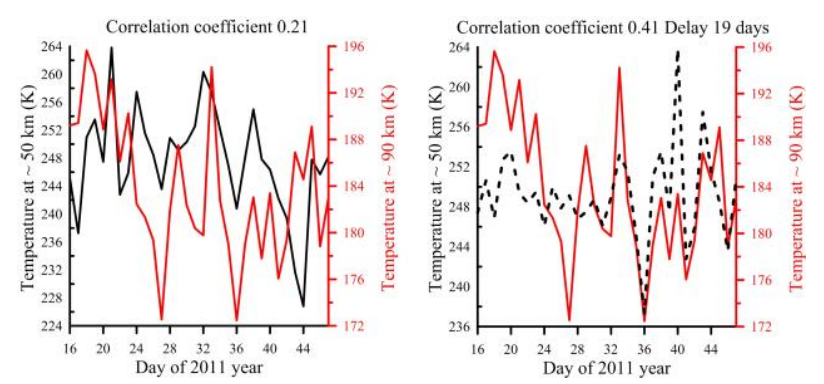

Figure 6. Daytime temperatures over Irkutsk at heights of $\sim 50$ and $\sim 90 \mathrm{~km}$, obtained by the AURA satellite. The black line is the temperature at $\sim 50 \mathrm{~km}$; the red line, the temperature at $\sim 90 \mathrm{~km}$; the black dotted line, the temperature at $\sim 50 \mathrm{~km}$ with a time shift to derive the maximum correlation coefficient

band, $834.0 \mathrm{~nm}, \sim 87 \mathrm{~km}$ ) obtained from spectrometric measurements at the ISTP SB RAS Geophysical Observatory $\left(51.8^{\circ} \mathrm{N}, 103.1^{\circ} \mathrm{E}\right.$, Torah) with a time resolution of $10 \mathrm{~min}$. The rotational temperature of the hydroxyl molecule reflects the temperature of the atmosphere at the mesopause. As a characteristic of atmospheric variability in the upper mesosphere, we utilized the standard deviations of the mesopause temperature $(K)$ in the night variation, which can be used to analyze the manifestation of wave activity with IGW periods at these heights. The method is described in detail in [Perminov et al., 2014a, b]. Measurements are made at night in the absence of dense clouds and full moon. Since series of spectrometric observation data are discontinuous, thereby limiting the capabilities of the correlation analysis, we have qualitatively compared manifestations of mesospheric and ionospheric activity and have identified the time intervals in which their behavior is consistent.

Figure 7 exemplifies interdiurnal variations in mesospheric and ionospheric activity for January 2014, 2017, and 2019.

\section{CONCLUSIONS}

Comprehensive study of the manifestation of wave activity with IGW periods in various regions of the atmosphere allowed us to assess the influence of wave activity in the stratosphere and planetary waves on wave activity at ionospheric heights.

The shear correlation coefficient between ionospheric and stratospheric activity for the annual interval varies in the range of 0.45 to 0.54 , and for the 27 -day interval it reaches $0.4-0.8$ in $70 \%$ of cases; $30 \%$ of the shear correlation coefficients less than 0.4 can be explained by the influence of variations in the neutral wind, geomagnetic activity, and non-stratospheric IGW sources. The optimal time shift varies over a wide range from 1 to 30 days. The delay in ionospheric activity relative to stratospheric activity can be explained by the fact that stratospheric activity is determined by the planetary wave maximum for the stratopause $(\sim 50 \mathrm{~km})$, whereas ionospheric activity is most strongly affected by disturbances at the mesopause $(\sim 90 \mathrm{~km})$. In this case, the time shift depends on the delay in the planetary wave phase in the mesopause region relative to that in the stratosphere.

Comparison between stratospheric activity and variations in characteristics of traveling ionospheric disturbances has revealed that a $\sim 15$ day shift in stratospheric activity results in a fairly high correlation between stratospheric activity and the disturbance of IGW characteristics ( 0.6). A delay of about 15 days in the disturbance of IGW characteristics may be explained by the corresponding delay in temperature variations at heights of the lower thermosphere relative to those at the altitude pressure level of $1 \mathrm{hPa}$. This version is confirmed by the close delay in temperature variations at heights of $\sim 50$ and $\sim 90 \mathrm{~km}$, obtained from AURA satellite data.

Comparative analysis of mesospheric and ionospheric activity variations has found time intervals in which their behavior is consistent.
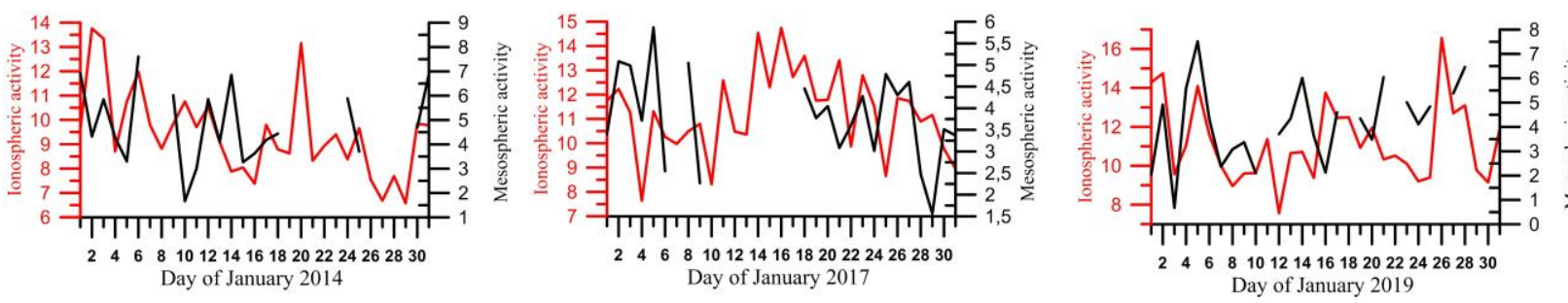

Figure 7. Day-to-day variations in ionospheric (red line, left axis in \%) and mesospheric (black line, right axis, K) activity 
The work was financially supported by RFBR under scientific project No. 20-05-00212 and by the Ministry of Higher Education and Science of the Russian Federation for conducting observations and data processing. The results were obtained using the equipment of Shared Equipment Center "Angara" [http://ckprf.ru/ckp/3056] and the Unique Research Facility "Irkutsk Incoherent Scatter Radar" [http://ckp-rf.ru/usu/ 77733].

\section{REFERENCES}

Bath M. Spectral Analysis in Geophysics. Elsevier Scientific Publishing Company, Amsterdam-Oxford-New York, 1974. $563 \mathrm{p}$.

Dell'Aquila A., Lucarini V., Ruti P.M., Calmanti S. Hayashi spectra of the northern hemisphere mid-latitude atmospheric variability in the NCEP-NCAR and ECMWF reanalyses. Climate Dynamics. 2005, vol. 25, no. 6, pp. 639-652.

Erokhin N.S., Mikhailovskaya L.A., Shalimov S.L. Propagation of large scale internal gravitational waves to ionospheric heights through wind structures in the lower and medium atmosphere. Geophys. Res. 2007a, iss. 7, pp. 53-64. (In Russiain).

Erokhin N.S., Zolnikova N.N., Mikhailovskaya L.A. Peculiarities of interaction of internal gravitational waves with temperature-wind structures of the atmosphere during their propagation into the ionosphere. Sovremennye problemy distantsionnogo zondirovaniya Zemli iz kosmosa. 2007b, vol. 2, pp. 84-89. (In Russian).

Goncharenko L., Zhang S.-R. Ionospheric signatures of sudden stratospheric warming: Ion temperature at middle latitude. Geophys. Res. Lett. 2008, vol. 35, L21103. DOI: 10.1029/ 2008 GL035684.

Goncharenko L.P., Chau J.L., Liu H.L., Coster A.J. Unexpected connections between the stratosphere and ionosphere. Geophys. Res. Lett. 2010, vol. 37, L10101. DOI: 10.1029/2010 GL043125.

Goncharenko L.P., Chau J.L., Condor P., Coster A., Benkevitch L. Ionospheric effects of sudden stratospheric warming during moderate-to-high solar activity: Case study of January 2013. Geophys. Res. Lett. 2013, vol. 40. DOI: 10.1002/grl.50980.

Hayashi Y. A generalized method of resolving disturbances into progressive and retrogressive waves by space Fourier and time cross-spectral analyses. J. Meteorol. Soc. Japan. 1971, vol. 49, no. 2, pp. 125-128.

Korenkov Y.N., Klimenko V.V., Klimenko M.V., Bessarab F.S., Korenkova N.A., Ratovsky K.G., Chernigovskaya M.A., Shcherbakov A.A., Sahai Y., Fagundes P.R., de Jesus R., de Abreu A.J., Condor P. The global thermospheric and ionospheric response to the 2008 minor sudden stratospheric warming event. J. Geophys. Res. 2012, vol. 117, A10309. DOI: 10.1029/2012JA018018.

Medvedev A.V., Ratovsky K.G., Tolstikov M.V., Alsatkin S.S., Scherbakov A.A. A statistical study of internal gravity wave characteristics using the combined Irkutsk Incoherent Scatter Radar and Digisonde data. J. Atmos. Solar-Terr.Phys. 2015, vol. 132, pp. 13-21. DOI: 10.1016/j.jastp.2015.06.012.

Medvedev A.V., Ratovsky K.G., Tolstikov M.V., Oinats A.V., Alsatkin S.S, Zherebtsov G.A. Relation of internal gravity wave anisotropy with neutral wind characteristics in the upper atmosphere. J. Geophys. Res. 2017, vol. 12, iss. 7, pp. 7567-7580. DOI: 10.1002/2017JA024103.

Pancheva D., Mukhtarov P. Stratospheric warmings: The atmosphere-ionosphere coupling paradigm. J. Atmos. SolarTerr. Phys. 2011, vol. 73, iss. 13, pp. 1697-1702. DOI: 10.1016/j.jastp.2011.03.006.

Perminov V.I., Semenov A.I., Pertsev N.N., Medvedeva I.V. Temperature variations in the mesopause region according to the hydroxyl-emission observations at midlatitudes. Geomagnetism and Aeronomy. 2014a, vol. 54, no. 2, pp. 230-239.

Perminov V.I., Semenov A.I., Medvedeva I.V., Zheleznov Yu.A. Variability of mesopause temperature from the hydroxyl airglow observations over midlatitudinal sites, Zvenigorod and Tory, Russia. Adv. Space Res. 2014b, vol. 54, pp. 25112517. DOI: 10.1016/j.asr.2014.01.027.

Pogoreltsev A.I., Savenkova E.N., Aniskina O.G., Ermakova T., Chen W., Wei K. Interannual and intraseasonal variability of stratospheric dynamics and stratosphere-troposphere coupling during northern winter. J. Atmos. Solar-Terr. Phys. 2015, vol. 136B, pp. 187-200.

Polyakova A.S., Chernigovskaya M.A., Perevalova N.P. Ionospheric Effects of Sudden Stratospheric Warmings in Eastern Siberia Region. J. Atmos. Solar-Terr. Phys. 2014, vol. 120, pp. 15-23. DOI: 10.1016/j.jastp.2014.08.011.

Shpynev B.G., Churilov S.M., Chernigovskaya M.A. Generation of waves by jet stream instabilities in winter polar stratosphere/mesosphere. J. Atmos. Solar-Terr. Phys. 2015, vol. 136, pp. 201-215. DOI: 10.1016/j.jastp.2015.07.005.

Suslov A.I., Erokhin N.S., Mikhailovskaya L.A., Artekha S.N., Gusev A.A. Modeling the passage of large-scale internal gravitational waves from the troposphere to the ionosphere. Sovremennye problemy distantsionnogo zondirovaniya Zemli iz kosmosa. 2017, vol. 14, no. 5, pp. 19-25. (In Russiain).

Tolstikov M.V., Medvedev A.V., Ratovsky K.G., Medvedeva I.V. Studies of dynamic characteristics of atmospheric planetary waves during stratospheric warmings 20062013. Proc. XXXI ${ }^{\text {th }}$ URSI General Assembly and Scientific Symposium (URSI GASS). Beijing, 2014, pp. 1-4. DOI: 10.1109/URSIGASS.2014.6929752.

Tolstikov M.V., Oinats A.V., Medvedeva I.V., Medvedev A.V., Ratovsky K.G., Nishitani N. Relation of traveling ionospheric disturbances characteristics with planetary waves in the middle atmosphere. Proc. PhotonIcs \& Electromagnetics Research Symposium - Spring (PIERS-Spring). Rome, Italy, 2019, pp. 2176-2182. DOI: 10.1109/PIERS-Spring46901. 2019.9017884. 2021).

URL: http://disc.gsfc.nasa.gov/Aura (accessed October 20, URL: $\quad$ ftp://ftp.ngdc.noaa.gov/STP/GEOMAGNETIC_ DATA/INDICES/KP AP (accessed October 20, 2021).

URL: http://ckp-rf.ru/ckp/3056 (accessed October 20, 2021). URL: http://ckp-rf.ru/usu/77733 (accessed October 20, 2021).

How to cite this article

Tolstikov M.V., Ratovsky K.G., Medvedeva I.V., Khabituev D.S. Estimated influence of stratospheric activity on the ionosphere according to measurements with ISTP SB RAS tools. Solar-Terrestrial Physics. 2021. Vol. 7. Iss. 4. P. 79-84. DOI: 10.12737/stp-74202108. 